\title{
Reimplante de mano con bloqueo continuo de plexo braquial y anestesia general reporte de caso
}

\author{
Ortiz JK. ${ }^{1}$, Palavicini N. ${ }^{1}$, Hernández J. ${ }^{1}$, Cuj A. ${ }^{1}$ \\ 1 Hospital de Alta Especialidad Dr. Gustavo A Rovirosa Pérez, Villahermosa, México.
}

Introducción: Reimplante es la recolocación de un segmento corporal amputado en su totalidad,la capacidad de reimplantar un segmento amputado a través de la microcirugía. Es un reto en la anestesiología por las diferentes etapas del proceso.

Material y Método: Paciente masculino de 45 años con amputación traumática por objeto cortocontundente de mano izquierda, con cinco horas de evolución, antecedentes de hipertensión, se propone reimplante de mano; se opta por manejo con bloqueo continuo de plexo braquial más anestesia general. Se reliaza bloqueo de plexo braquial supraclavicular ecoguiado y colocación de catéter más anestesia con intubación de secuencia rápida.

Resultados: Se mantiene estable hemodinamicamente y con bomba elastomérica para control de dolor postoperatorio con EVA de 1.

Conclusiones: EL bloqueo continuo del plexo braquial mejora la perfusión tisular tras la cirugía de reimplante de extremidad. Esta técnica es especialmente beneficiosa para prevenir el vasoespasmo en el tejido reconstruido en el período postoperatorio y disminuir la dosis de opiodes en el perioperatorio.

https://doi.org/10.25237/congresoclasa2019.17 